\title{
SEASONAL GHANGES OF SPEED IN TEMPERATE VALLEY GLACIERS
}

For the second session of the Symposium the chair was taken by Dr. B. Fristrup. The first paper was by Mr. G. R. Elliston on "Seasonal changes of speed in temperate valley glaciers".

$\mathrm{Mr}$. Elliston started by reviewing previous work in which variations of glacier velocity at different seasons of the year had been discovered, and then turned to his own recent work on the Gornergletscher, where a series of stakes along a longitudinal line down the glacier had been surveyed throughout the year. The top stake, with a mean velocity of $17 \mathrm{~cm}$./day, moved 23 per cent faster than average during August, fell off to about 2 per cent less than average by February, accelerated to 35 per cent above average by May and then slowed down to 5 per cent below average. Similarly a lower stake, whose mean velocity in r $959-60$ was $6.55 \mathrm{~cm}$./day and in $1960-61$ was $6 \cdot 65 \mathrm{~cm}$./day varied from month to month from 34 per cent slower than average in November to December to $4^{\circ}$ per cent faster than average in May to June.

Mr. Elliston then discussed short-term variations in glacier velocity emphasizing the importance of studying possible errors, particularly those arising from horizontal refraction. However he felt that after these had been allowed for there were significant variations, even at a place where the ice was $280 \mathrm{~m}$. deep, the surface gradient negligible and no crevasses present.

\section{DISCUSSION OF MR. G. R. ELLISTON'S PAPER}

DR. J. F. NyE: I suppose the velocity of a stake can vary on two accounts, either because time has run on or because the stake has moved to a new place on the glacier. Now you only want the first of these; how do you sort them out?

Mr. Elliston: Around each stake whose velocity was measured, three other stakes were placed to form a square of sides $30 \mathrm{~m}$. in length, and the distortion in shape of the figure was measured at each survey to give the strain-rates present in the ice at that point. If an increase in surface velocity results from the increasing gradient of the bedrock, the strainrate measured in the down-glacier direction should become at first more tensile and then less so as the glacier adjusts its shape to the change in slope. If an increased surface velocity is due to a temporary thickening of the glacier by the passage of an increased mass of ice in a kinematic wave, the down-glacier strain-rate might be expected to become at first more compressive and then to return to its original value. It would be very difficult to separate out the effect of something like a wave passing through the stake group from the effects of bedrock topography unless you were certain of the bedrock topography, and I am not yet sure whether our own measurements are accurate enough to separate out these two causes. The bedrock topography is accurately fixed by over I, 400 soundings in the ablation zone. 